\title{
Percepção de gestores acerca da atuação e inserção de terapeutas ocupacionais na atenção básica à saúde
}

\author{
Erickson Franklin dos Santos Miranda ${ }^{a}$ (D), Cláudia Fell Amado ${ }^{a}$ (D), \\ Thayane Pereira da Silva Ferreira ${ }^{\mathrm{b}}$
}

a'Universidade Federal da Paraíba - UFPB, João Pessoa, PB, Brasil.

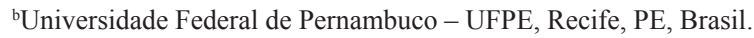

\begin{abstract}
Resumo: Introdução: A terapia ocupacional é uma profissão da área de saúde que tem interfaces na educação e no campo social, cujas ações objetivam a participação dos indivíduos em ocupações cotidianas que promovem a construção de sua identidade, saúde e bem-estar. Sendo assim, o terapeuta ocupacional está apto para atuar em diversos pontos de atenção à saúde, dentre eles a Atenção Básica à Saúde. Nesse sentido, é importante que os gestores conheçam os profissionais, suas particularidades e a função que desempenham em cada equipe e serviço de saúde. O reconhecimento e valorização dos papéis desenvolvidos no âmbito da Atenção Básica por esses atores facilita o desenvolvimento de ações adequadas para cada coletivo em suas especificidades culturais. Objetivo: Descrever a percepção dos gestores de saúde da Atenção Básica à Saúde acerca da atuação e inserção da terapia ocupacional. Método: Trata-se de uma pesquisa descritiva exploratória de abordagem qualitativa, que foi realizada na Secretaria Municipal de Saúde e nos cinco Distritos Sanitários distribuídos no território de João Pessoa-PB, com gestores ligados à Atenção Básica no período de junho a agosto de 2018. Foi utilizada uma entrevista semiestruturada pelos pesquisadores e os dados foram analisados por meio da técnica de Análise do Conteúdo. Resultados: Participaram da pesquisa 18 gestores, de ambos os sexos. Percebe-se que os gestores compreendem que a terapia ocupacional está voltada para as atividades cotidianas dos sujeitos, para a adaptação de utensílios, mas a confundem com a fisioterapia. Quanto à contratação, referem que a mesma se dá por meio de seleção de currículo e entrevista, havendo influência de indicações políticas. Conclusão: Assim, devem ser ampliadas as discussões sobre a terapia ocupacional chegando até os espaços de gestão, no sentido de ampliar o reconhecimento e a inserção da profissão na Atenção Básica à saúde, visando um atendimento mais universal, equânime e integral que responda às necessidades dos usuários.
\end{abstract}

Palavras-chave: Terapia Ocupacional, Atenção Primária à Saúde, Gestão de Serviços de Saúde.

\section{Perception of managers about the practice and insertion of occupational therapists in basic health care}

\begin{abstract}
Introduction: Occupational therapy is a health profession that has interfaces in education and in the social field, whose actions aim at the participation of individuals in everyday occupations that promote the construction of their identity, health and well-being. Accordingly, the occupational therapist is able to act in several health care spots, among them the Primary Health Care. In this sense, it is important that managers know the professionals, their particularities and the role they play in each health staff and facility. The recognition and appreciation of the roles developed in the scope of Primary Health Care by these actors facilitates the development of appropriate actions for each collective in its cultural specificities. Objective: To describe the perception of the health managers of the Primary Health Care about the practice and insertion of the occupational therapy. Method: This is a qualitative exploratory descriptive research that was carried out in the Municipal Health Department and in the five Health
\end{abstract}

Autor para correspondência: Cláudia Fell Amado, Universidade Federal da Paraíba, Cidade Universitária, s/n, Castelo Branco III, CEP 58051-085, João Pessoa, PB, Brasil, e-mail: claudiafell.saude@gmail.com

Recebido em Nov. 7, 2018; 1ª Revisão em Jan. 18, 2019; 2a Revisão em Mar. 24, 2019; Aceito em Maio 10, 2019. 
Districts distributed in the territory of João Pessoa-PB, with managers linked to Primary Health Care from June to August 2018. A semistructured interview was used by the researchers and the data were analyzed using the Content Analysis technique. Results: 18 managers, of both sexes, participated in the study. It is noticed that the managers understand that the occupational therapy is directed to the daily activities of the subjects, for the adaptation of utensils, but they confuse it with physiotherapy. Regarding hiring, they mention that it is done through selection of curriculum and interview, there being influence of political indications. Conclusion: Thus, discussions on occupational therapy should be broadened to reach management spaces in order to broaden the recognition and insertion of the profession in Primary Health Care level, aiming at a more universal, equitable and integral service that responds to the users' needs.

Keywords: Occupational Therapy, Primary Health Care, Health Services Administration.

\section{Introdução}

A luta pela ampliaçáo dos direitos sociais que ocorreu na Reforma Sanitária brasileira resultou na implantação do Sistema Único de Saúde (SUS), criado pela Constituição Federal Brasileira em 1988, que traz no seu artigo $196^{\circ}$ "[...] a saúde como um direito de todos e dever do Estado", regulamentado pela Lei 8080 de 1990 (BRASIL, 1990, p. 01).

Os princípios doutrinários que sustentam o SUS são a universalidade do acesso, a integralidade do cuidado e a equidade, implicando em uma nova maneira de ofertar atenção à saúde, ampliada e complexa, com açôes voltadas para a promoção, prevenção, proteção e recuperação da saúde (assistência e reabilitação) para todos (ROCHA; PAIVA; OLIVEIRA, 2012; BRASIL, 2012, 2017a).

Nesse sentido, para a construção e reordenamento dos serviços e açôes de saúde, propostos pelo SUS, as diretrizes da Atenção Básica devem ser o eixo norteador, a principal porta de entrada para o sistema, garantindo o cuidado a todos e aos problemas de saúde mais frequentes na população (BRASIL, 1990; CAMPOS et al., 2008).

A Atenção Básica em Saúde - ABS pode ser caracterizada como

O conjunto de açôes de saúde individuais, familiares e coletivas que envolvem promoção, prevenção, proteção, diagnóstico, tratamento, reabilitação, redução de danos, cuidados paliativos e vigilância em saúde, desenvolvida por meio de práticas de cuidado integrado e gestão qualificada, realizada com equipe multiprofissional e dirigida à população em território definido, sobre as quais as equipes assumem responsabilidade sanitária (BRASIL, 2017b, p. 68).

Sendo assim, esse potente espaço está adscrito em um território onde os profissionais precisam compreender as nuances, formas e sentidos que os indivíduos produzem acerca da vida e assim, ofertarem um cuidado integral para o usuário de forma multiprofissional e interdisciplinar (SANTOS, 2003; CECCIM, 2005; MARCOLINO et al., 2016). Esse território vai além do ambiente geográfico, caracteriza-se como um espaço de troca entre as pessoas, sendo palco e mediador das relaçóes (SANTOS, 2003; CECCIM, 2005).

Tendo em vista os inúmeros desafios para melhor atender os objetivos propostos para o Sistema Único de Saúde, bem como para efetivar os princípios que o sustentam, o Ministério da Saúde implantou, em 1994, o Programa de Saúde da Família (PSF), atualmente reconhecido como Estratégia Saúde da Família (ESF) tendo como meta a reorganização e a reestruturação da Atenção Básica (LIMA; FALCÃO, 2014).

Nessa perspectiva, aos passos da ampliação, deu a capacidade de resposta à maior parte dos problemas de saúde da população na $A B S$ e apoiar a inserção da ESF, o Ministério da Saúde, a partir de experiências municipais e de debates nacionais, criou os Núcleos de Apoio à Saúde da Família, que na Nova Política Nacional de Atenção Básica (PNAB) passam a ser Núcleos Ampliados de Saúde da Família (NASF). Os NASF foram criados com o objetivo de apoiar a consolidação da Atençáo Básica no Brasil, ampliando as ofertas de saúde na rede de serviços, assim como a resolutividade e a abrangência das ações (BRASIL, 2008, 2012, 2014a, 2017b).

O NASF pode ser constituído por vários profissionais, entre eles, o terapeuta ocupacional (T.O.). A terapia ocupacional é uma profissão da área de saúde que tem interfaces na educação e no campo social, cujas açôes objetivam a "[...] participação dos indivíduos em ocupaçóes cotidianas que promovem a construçáo de sua identidade, saúde e bem-estar" (UNIVERSIDADE..., 2018, p. 01). Quando o indivíduo sofre alteraçóes na participação e engajamento em suas ocupaçôes, seja por questáo física, sensorial, mental e/ou social ou pelas modificaçóes do ambiente, o terapeuta 
ocupacional poderá intervir com seu conhecimento nas diversas dimensóes, pessoal, coletiva e cultural. Sendo assim, o terapeuta ocupacional está apto para atuar em diversos pontos de atenção à saúde, dentre eles a Atenção Básica (UNIVERSIDADE..., 2018).

Partindo dessa compreensão de Atenção Básica, de território e da terapia ocupacional, o terapeuta ocupacional atuará a partir das narrativas do cotidiano (GALHEIGO, 2003), dos encontros com as pessoas e locais de convívio. Nesse ponto de atenção em que as complexidades dos sujeitos se apresentam, a especificidade técnica desse profissional estará voltada para a relação entre pessoa-cotidiano-ocupação, sendo sensível para trabalhar o significado dessa relação (BAISSI; MAXTA, 2013).

De forma específica, dentre as açôes que podem ser desenvolvidas pelo terapeuta ocupacional na Atenção Básica, destacam-se: mapear o território, matriciar as equipes, identificar as demandas e realizar açóes que se preocupem com os indivíduos e coletivos que sofrem de alguma alteração física, mental e/ou social, a fim de prevenir agravos e promover autonomia e independência para os indivíduos no cotidiano. O terapeuta ocupacional exerce também o papel de articulador sob a perspectiva intersetorial, sendo um profissional que dialoga com outros equipamentos e que auxilia os usuários a estarem inseridos na rede de seus territórios (ROCHA; PAIVA; OLIVEIRA, 2012). Tais objetivos perpassam a detecção de pessoas que necessitem da reabilitação física e dos cuidados em saúde mental, a prescrição de Tecnologia Assistiva, adaptaçóes da rotina, e o enfrentamento das violências (CABRAL; BREGALDA, 2017; ANTUNES; ROCHA, 2011).

A partir do que é significativo para o território, e considerando a diversidade de aspectos tanto do ponto de vista coletivo quanto individual - dentro e fora da unidade de saúde, o terapeuta ocupacional utilizará de abordagens que auxiliarão o desenvolvimento dos objetivos pretendidos.

No contexto da Saúde no município de Joáo Pessoa, a Diretoria de Atenção à Saúde, segundo a Secretaria Municipal de Saúde (JOÃO PESSOA, 2018, p. 01), tem como objetivo "[...] a formação e o desenvolvimento da rede de cuidados progressivos em saúde no SUS municipal" e é subdivida em três Gerências: da Atenção Básica, de Serviços Especializados e Hospitalar. A Gerência da Atenção Básica, por sua vez, divide-se em 05 distritos sanitários, circunscrevendo o total de 200 Unidades da Saúde da Família divididas em 100 espaços físicos. De acordo com a Gerência de Atenção Básica, nesse contexto, há uma terapeuta ocupacional contratada em João Pessoa (2014).
Conforme o Ministério da Saúde (BRASIL, 2014b), quando se trata da contratação de profissionais para o NASF, é necessário que a gestão em saúde do município esteja atenta às questôes relacionadas ao diagnóstico situacional do território para o levantamento de demandas e necessidades dos usuários. Além disso, é preciso que seja realizado a desprecarização e qualificaçáo do vínculo e dos processos de trabalho dos profissionais do NASF, ainda no momento da implantaçáo desse serviço e no tocante a infraestrutura, logística e diretrizes.

Considerando as políticas públicas como eixo norteador dos serviços e ações em saúde, os gestores possuem papel fundamental na sua consolidação. Esse papel deve contribuir para a potencialização dos processos de trabalho, a conciliaçáo dos dilemas do cotidiano e a seguridade dos princípios e diretrizes do sistema de saúde, assim como para a organização, planejamento e execução de açôes de cuidado em saúde, gerando um arcabouço técnico-científico de qualidade, e facilitação ativa do diálogo entre os usuários e profissionais. Desse modo, abre-se espaço para a participação e engajamento da populaçấo e dos trabalhadores de saúde nas tomadas de decisão (BRASIL, 1990; SCHRAIBER et al., 1999).

Merhy, Malta e Santos (2018), refletindo sobre esse ator frente à elaboração de açóes, consideram que se estas forem realizadas de forma harmoniosa alcançam resultados efetivos. Essa forma de pensar a gestão em saúde leva em consideração a participação de outros atores, usuários e trabalhadores, com o objetivo de dar visibilidade e efetivar todas as ações, conhecendo e valorizando o importante papel de cada um desses componentes (FURLAN; OLIVEIRA, 2017; CRUZ; SOUZA; EMMEL, 2014). Nesse sentido, é importante que os gestores conheçam os profissionais, suas particularidades e a função que desempenham em cada equipe e serviço de saúde. O reconhecimento da importância e valorização dos papéis desenvolvidos no âmbito da Atenção Básica por esses atores facilita o desenvolvimento de açóes adequadas para cada coletivo em suas especificidades culturais. Sendo assim, o conhecimento técnico, em consonância com a capacidade de pensar e agir evoca habilidades de ser e realizar de cada gestor (MIRANDA, 2014).

Considerando o que foi exposto, as práticas desenvolvidas em uma disciplina do curso de terapia ocupacional da Universidade Federal da Paraíba, que tem ênfase o contexto da Atenção Básica à Saúde, despertaram o desejo de nos aprofundarmos nos conhecimentos produzidos sobre essa temática, inspirados nas experiências das práticas em atendimentos domiciliares e em grupos 
com diferentes faixas etárias e imbuídos nas reflexôes das supervisóes da disciplina. A inquietação sobre a escassez de terapeutas ocupacionais na Atenção Básica e sensibilização acerca da inserção de mais profissionais de terapia ocupacional nesse ponto de atenção é o que motivou a realização desta. Assumimos, pois, um desafio: ir a campo para iniciar o diálogo, elemento essencial para aquisição de conhecimento. Nesse sentido, este estudo tem como objetivo descrever a percepçáo dos gestores de saúde da Atenção Básica acerca da atuação e inserção da terapia ocupacional neste nível de atençáo.

\section{Método}

Trata-se de uma pesquisa descritiva exploratória de abordagem qualitativa, que foi realizada na Secretaria Municipal de Saúde e nos 05 Distritos Sanitários distribuídos no território de João Pessoa-PB.

A partir do organograma construído pelos pesquisadores a partir das informaçóes dadas pela Secretaria Municipal de Saúde, foram identificados os seguintes gestores: Secretário de Saúde, Diretor da Atenção à Saúde, Gerente da Atenção Básica, 03 Técnicos da Gerência da Atenção Básica, 15 gestores dos Distritos Sanitários (05 gerais, 05 administrativos e 05 técnicos), totalizando assim 21 gestores ligados à Atenção Básica, que estavam aptos a participarem da pesquisa, respondendo o critério de inclusão da pesquisa de estarem no cargo de gestáo em exercício.

Os dados foram coletados no período de junho a agosto de 2018 por meio da realização de uma entrevista semiestruturada, elaborada, aplicada e gravada pelos pesquisadores. O conteúdo da entrevista abrangia uma primeira parte com a identificaçâo dos participantes, formação profissional, tempo na gestão e, em seguida, questôes abertas acerca da compreensão e percepção dos gestores sobre a atuação e inserção dos terapeutas ocupacionais na Atenção Básica, desde o que eles compreendiam sobre terapia ocupacional, as demandas acolhidas por esse profissional, as contribuiçóes para a Atenção Básica até a forma de contratação dos profissionais desse nível de atenção. Todos os participantes foram contatados previamente e informados a respeito $\mathrm{da}$ pesquisa, para que, posteriormente, fossem agendadas as entrevistas. Foram feitos agendamentos nos locais de preferência dos participantes, sendo a maior parte realizada nos seus locais de trabalho. As datas e horários das entrevistas foram igualmente pactuados com os participantes.

Os dados oriundos da entrevista foram transcritos na totalidade e analisados por meio da análise de conteúdo, descrita por Bardin (1977). Segundo a autora, a análise de conteúdo é uma técnica de investigação por descrição objetiva e sistemática do conteúdo manifesto da comunicação, focando nas variáveis das representaçóes sociais (BARDIN, 1977). A análise foi realizada de acordo com as seguintes etapas: pré-análise, exploração do material e categorização, interferência e interpretação.

Após as transcriçôes das entrevistas, as mesmas foram lidas pelos pesquisadores para que fossem grifadas as ideias que mais se repetiam. Em seguida, foram organizadas em núcleos de sentido, que compóe as categorias temáticas, sendo elas: 1- Percepções sobre a terapia ocupacional; 2- (Des) encontros entre a Fisioterapia e terapia ocupacional e; 3- Processos de contratação de terapeutas ocupacionais. Para discussão dos resultados, foram transcritos trechos das entrevistas de alguns gestores, sendo garantida a preservação de sua identidade. Os participantes foram identificados pelo termo "gestor" seguido por um número referente à ordem das entrevistas.

O estudo teve a aprovação do Comitê de Ética e Pesquisa do Centro de Ciências Médicas da Universidade Federal da Paraíba e a anuência da Secretaria Municipal de Saúde de João Pessoa, por meio da Gerência de Educação em Saúde.

\section{Resultados e Discussão}

Dos 21 gestores aptos a participarem do estudo, 18 aceitaram responder à entrevista, 01 gestor não aceitou e 02 gestores estavam afastados por férias no período da coleta. Dos dezoito gestores participantes, dezesseis eram do sexo feminino e dois do masculino, cuja idade variou de 25 a 56 anos. Com relação às profissôes, 09 eram enfermeiras, 02 eram da área de Administração e as demais eram 01 nutricionistas, 02 psicólogas, 02 fonoaudiólogas e 01 educadoras física. A média de tempo desses profissionais na gestâo foi de 5,5 anos.

\subsection{Percepções sobre a terapia ocupacional}

\subsubsection{Percepção sobre a atuação}

10 gestores ao se referirem à atuação do terapeuta ocupacional, citaram termos como ocupação, atividades, desempenho e cotidiano. Os participantes ainda trouxeram a ideia de que esse profissional atua para ajudar a realização das atividades de vida diária de forma independente. 
Eu acredito que o terapeuta ocupacional vem desempenhando, observando, acompanhado as pessoas no desempenho dessas atividades do cotidiano delas, dos movimentos, e assim, ele vem também auxiliar quando tem prejuizos nesses movimentos (Gestora 01).

Um usuário chega na Unidade e tem dificuldade, por exemplo, de se vestir... é o terapeuta ocupacional que [...] vê uma maneira de ajudar, aquele paciente para ele ser independente [...] eu definiria como um trabalho diferencial (Gestora 02).

É uma área de estudo e também de formação, cujo profissional está mais voltado para a funcionalidade do paciente, adaptação do ambiente, dos instrumentos da vida diária (Gestor 04).

Vem para facilitar a ocupação, para facilitar a vida dessas pessoas que precisam de alguma forma de cuidado, facilitar o dia a dia dessas pessoas com algum grau de incapacidade (Gestora 07).

Os termos contidos nas falas dos participantes, apesar de partirem do senso comum, remetem a elementos importantes que, em conjunto, fazem parte da construção de saberes da terapia ocupacional, constituindo a sua identidade profissional e norteando as práticas dos terapeutas ocupacionais. Segundo Lima, Okuma e Pastore (2013), os conceitos evidenciados como "ocupaçáo" e "cotidiano", por exemplo, são amplamente estudados pela comunidade científica da terapia ocupacional e revelam discussóes importantes para a formação e a prática dessa profissão. Assim, perspectivas diferentes podem surgir para falar de um mesmo conceito, o que engrandece o escopo teórico da profissão.

Desse modo, a AOTA (ASSOCIAÇÃO..., 2013) quando se refere a ocupaçáo humana se dedica a construir uma perspectiva a partir do que os sujeitos sáo capazes de realizar, organizando, classificando e tipificando os desempenhos ocupacionais em diversas dimensóes. Galheigo (2003), por sua vez, aponta, de forma até poética, o cotidiano dos indivíduos onde essas ocupaçōes se manifestam de diversas formas e maneiras, não desvalidando a outra perspectiva, porém ampliando o olhar.

Dessa forma, partindo-se para a compreensão do que vem a ser a identidade profissional, Dubar (2006) refere que este constructo diz respeito à maneira socialmente reconhecida, pela qual os indivíduos se relacionam uns com os outros no âmbito do trabalho e do emprego. O mesmo autor refere que a identidade profissional se constrói através da transação biográfica e relacional, ou seja, de identidade para si e de identidade para o outro, articuladas e processadas por mecanismos de pertencimento e de atribuição.
De acordo com Carvalho (2012), a identidade profissional é carregada de sentidos e significados, além de fatos sócio-históricos que, temporária ou definitivamente, estabelecem uma compreensão de como as profissóes se constituem a partir do seu objeto, objetivos e recursos de e para o trabalho. Essa construção da identidade profissional está atrelada a um processo de reconhecimento, que na terapia ocupacional é uma bandeira de luta. O reconhecimento, para a autora, articula-se com esse olhar social, que identifica na prática o que as profissóes realizam no mundo. O oposto disso é o desconhecimento que acaba por levar a não inserçáo de terapeutas ocupacionais nos espaços onde há a necessidade desse profissional. Para tanto, enquanto terapeutas ocupacionais, precisamos lutar e ocupar os espaços que ainda náo estáo sendo ocupados em diversos setores e serviços, incluindo os da Atenção Básica.

Embora os gestores tragam em suas falas temáticas centrais da atuação e formação dos terapeutas ocupacionais, vale ressaltar que dentro da atenção básica à saúde essa atuação perpassa por diversas açôes que são preconizadas nesse ponto de atenção. $\mathrm{O}$ vínculo com a comunidade e o atendimento às necessidades dela, a importância para o controle social do serviço de saúde, visitas domiciliares, grupos com intuito terapêutico, articulação intersetorial, entre outras açôes com foco na prevençấo de agravos, promoção da saúde e do cotidiano (CABRAL; BREGALDA, 2017).

Ainda que alguns gestores tragam em suas respostas elementos que se relacionam com a atuação do terapeuta ocupacional, como descrito no trecho abaixo, percebe-se alguma confusão sobre o que esse profissional faz, como se vê abaixo:

\section{É como se fosse uma especialização bem mais aprofundada do conhecimento, da pessoa, da questão do coletivo [...]. A terapia ocupacional é uma atividade (Gestora 03).}

Esse desconhecimento ou a confusão quanto à atuação desse profissional podem estar relacionados à predominância, nos espaços de formação em saúde, de um formato uniprofissional. De acordo com Peduzzi (2016), esse formato não favorece o diálogo entre as profissões, gerando uma deficiência na prática dentro dos serviços e no diálogo entre as profissôes, que se estende até chegar aos cargos de gestão. Essa deficiência favorece o desconhecimento e a não inserçấo de alguns profissionais na Rede de Atenção à Saúde. No sentido de superar esse paradigma da Uniprofissionalidade e deslocar o olhar para as necessidades dos usuários que precisam de um atendimento integral e de qualidade, a EIP tem 
sido apontada por vários estudos como uma estratégia capaz de reorientar a formaçáo de profissionais a partir do desenvolvimento de práticas colaborativas que respondam às necessidades dos usuários de forma equânime (WORLD..., 2010).

A Educação Interprofissional - EIP é definida como um modelo de formação que se estabelece a partir de açôes articuladas entre dois ou mais cursos da saúde, podendo contribuir para mudanças que melhorem a colaboração entre os profissionais e a qualidade da atençáo dispensada aos usuários. Reeves et al. (2013) referem que a EIP é uma intervenção em que os indivíduos de mais de uma profissão da saúde aprendem em conjunto, de forma interativa, tendo como propósito explícito a melhora na colaboração interprofissional.

Ainda sobre a EIP, a Organização Panamericana de Saúde (ORGANIZAÇĀO..., 2016, p. 3) refere:

A EIP é necessária para preparar a força de trabalho em saúde para envolvê-la em iniciativas de colaboração e responder às necessidades locais de saúde em um ambiente dinâmico. Portanto, a EIP é uma estratégia importante que melhora a capacidades dos recursos humanos da saúde e os resultados, e, em última instância, fortalece os sistemas de saúde.

Para a terapia ocupacional, no contexto da EIP e partindo desse movimento de assumir a identidade profissional e fazer com que a profissão seja reconhecida, abre-se um espaço de trocas de saberes, onde os aspectos comuns e específicos de cada profissão podem se encontrar em favor da populaçáo assistida pelos profissionais de saúde.

\subsubsection{Percepção sobre o público atendido pelo terapeuta ocupacional}

Quando questionados acerca dos casos e encaminhamentos para o terapeuta ocupacional, 09 dos participantes relacionaram sua atuação nesses casos frente a duas grandes áreas de cuidado dentro da saúde: a reabilitação física e o cuidado em saúde mental. Também ressaltaram a importância da intervenção desse profissional à grupos, principalmente de idosos.

Esse profissional está mais envolvido com essa questão de distúrbios físicos, emocionais, eles entram mais nessa questão para tentar apoiar pessoas que tem dificuldades emocionais, sociais (Gestora 05).
Ele vai conseguir observar o diagnóstico do território, os perfis dos usuários, necessidades motoras, necessidades psíquicas, necessidades afetivas, de forma ou individual ou grupal (Gestora 09).

Atua com reabilitação de pessoas que tiveram alguma sequela ou pessoas que tenham algum transtorno de nascença (Gestora 10).

Desenvolve trabalho, grupos, no sentido da saúde mental das pessoas (Gestora 17).

A compreensão dos gestores acerca das áreas de atuação da terapia ocupacional voltada para a inserção nas áreas de Reabilitação física e nos cuidados em saúde mental relaciona-se à construção histórica da profissão e da formação desses profissionais. Nesse processo histórico, destaca-se que entre as Grandes Guerras foi se estabelecendo a identidade no cuidado de pessoas mutiladas pelo confronto e em outro momento, a identificaçáo nos cuidados em saúde mental no início do movimento psiquiátrico com o Tratamento Moral e posteriormente, na luta antimanicomial.

No que se refere à formação em terapia ocupacional, na década de 1960, profissionais recém-formados, professores e coordenadores dos cursos de formação profissional buscaram o reconhecimento desses cursos como de nível superior, como um caminho para posterior regulamentação profissional. De acordo com Silva (2017), a busca por esse reconhecimento refletia a expectativa desses profissionais em torno $\mathrm{da}$ elaboração de uma identidade profissional, que lhes garantisse o controle e a determinação de seu próprio trabalho, uma vez que sua prática era desenvolvida sob o domínio médico. Nesse contexto, o autor afirma que os terapeutas ocupacionais tinham o desafio de articular duas perspectivas para delimitar o seu objeto de trabalho - a Reabilitação Física e a Psiquiatria.

Outro aspecto relacionado ao processo histórico de formação em terapia ocupacional, diz respeito ao fato de que inicialmente, o curso de formação na área surgiu como Curso de Reabilitação, destinado a formação de fisioterapeutas e terapeutas ocupacionais, que se diferenciava por algumas disciplinas. De acordo com terapeutas ocupacionais entrevistadas no estudo de Battistel (2016), na formação em terapia ocupacional destacavam-se as perspectivas/disciplinas de Reabilitação Física e Psiquiatria.

Mais tarde, a expansão dos cursos de formação em terapia ocupacional favoreceu a elaboração de um currículo mínimo, aprovado pelo Conselho Federal de Educação (CFE), em 1983. O rol de disciplinas do currículo, as que tratavam do exercício profissional da terapia ocupacional (Terapia Ocupacional Aplicada 
e Estágios) estavam orientadas predominantemente pelas perspectivas da Reabilitação Física e da Psiquiatria (SILVA, 2017).

Os aspectos citados reforçam a relação existente entre o desenvolvimento da formação em terapia ocupacional, com predomínio das duas grandes áreas citadas, e a maneira como os gestores percebem as áreas de atuação da terapia ocupacional.

No âmbito da Saúde Mental, a terapia ocupacional se propóe a efetivar as políticas públicas dessa área, auxiliando os usuários ao retorno a uma "vida ocupacional significativa” (DOMINGOS; KEBBE, 2016, p. 307), uma vez que a Saúde Mental é uma área de conhecimento e de prática que para além de visar o sofrimento mental, diagnosticando e tratando, está relacionada à prevenção e promoção à saúde, buscando a reabilitação e reinserção social do indivíduo (BRASIL, 2003).

Rocha, Paiva e Oliveira (2012, p. 355) ressaltam que

Embora a terapia ocupacional seja reconhecida como uma das categorias profissionais que possuem atributos para agir na saúde mental, ela possui competências específicas que possibilitam também atuar no âmbito da promoção, prevenção, assistência e reabilitação em outras áreas definidas como estratégicas pelo MS para o NASF, como na saúde da criança e do jovem, na reabilitação e saúde integral da pessoa com deficiência e idosa, na saúde da mulher, em práticas corporais, além de outras atividades e açóes desenvolvidas nas APS.

As autoras reforçam ainda a importância desse profissional inserido no NASF, auxiliando no matriciamento das equipes da saúde da família no que diz respeito

[...] às deficiências, saúde mental, alterações no desenvolvimento, violência, atividades do cotidiano, atividade lúdica e laboral, tecnologias assistivas (ROCHA; PAIVA; OLIVEIRA, 2012, p. 357).

Farias (2007) aponta que na reabilitação física, o terapeuta ocupacional precisa ter conhecimento sobre o funcionamento do corpo humano em sua forma típica e atípica, considerando as patologias, e no que isso influencia no desempenho ocupacional das pessoas. Ela ainda afirma que alcançando essa compreensão, o terapeuta ocupacional, deve se utilizar de instrumentais que atendam às necessidades do desempenho ocupacional de cada sujeito.
Carvalho (2012) aborda ainda um outro aspecto relacionado à população atendida pela terapia ocupacional. A autora refere o seguinte:

A população alvo das intervençóes em terapia ocupacional tem se caracterizado historicamente pela presença, em ampla diversidade e graduação, de alguma vulnerabilidade de saúde ou social; além disso, a profissão procura trazer para seu campo de reflexão teórico e para suas ações práticas o compromisso com as necessidades objetivas e subjetivas da população atendida, a partir de uma visão ampliada de saúde enredada à construçấo de direitos fundamentais (saúde, lazer, educação, liberdade de expressão, convívio social e etc.) (CARVALHO, 2012, p. 366).

A autora destaca que o olhar desse profissional vai além das necessidades de saúde e alcança as vulnerabilidades sociais da população atendida. Essa ampliação do olhar também serve para entender quais recursos o terapeuta ocupacional utilizará para alcançar os objetivos de sua intervenção e atender as necessidades dos usuários de acordo com os serviços e as políticas públicas nos quais ele esteja inserido.

Nesse sentido, fica evidenciado a amplitude e a importância da atuação do terapeuta ocupacional frente às demandas de reabilitação física, dos cuidados em saúde mental e de outros grupos inseridos na Atenção Básica.

Ainda no que diz respeito ao público atendido, de acordo 09 gestores, a atuaçáo do terapeuta ocupacional ocorre junto a pessoas que necessitam de adaptaçóes no ambiente ou em utensílios do cotidiano para a execução de atividades de vida diária.

A terapia ocupacional, pelo que eu entendo trabalha adaptando as situaçôes pra vida diária para o cotidiano dessa pessoa, na independência (Gestora 10).

O terapeuta ocupacional ajudaria a estar confeccionando produtos e materiais que facilitassem a vida desse usuário. Que a gente sabe que muitas das vezes são as adaptaçóes que o terapeuta ocupacional faz que ajudam aquele usuário a se alimentar melhor, a escrever, a ter acesso ao computador (Gestora 06).

Esse profissional está muito voltado para adaptaçāo dos instrumentos da vida diária dele, de garfo, colher, cadeira, cama, então essa parte funcional de adaptação de materiais (Gestora 04).

A Tecnologia Assistiva é uma das áreas nas quais a terapia ocupacional se insere e que trata de 
recursos que auxiliam na sua prática, sendo também apontada pelos gestores como uma característica da prática desse profissional. Esse aspecto demarca uma visão interessante sobre como o uso da Tecnologia Assistiva nas intervençôes, como se materializasse um fazer, demarcando o que o profissional e sua profissão realizam. Isso traz benefícios sobre o reconhecimento, mas pode limitar a percepção com relação a uma prática profissional, reduzindo-a apenas ao uso deste recurso.

Os dispositivos de TA podem ser utilizados nas questốes de déficits na comunicação, na oralizaçáo, na acuidade auditiva, nas questóes visuais, na postura e mobilidade e de ambiente. Assim, não apenas o terapeuta ocupacional estará envolvido nessa construçáo de pensar a Tecnologia Assistiva como recurso terapêutico, mas junto desse profissional, estarão ainda o fonoaudiólogo, o fisioterapeuta, o engenheiro (de produção, por exemplo), entre outros (PELOZI, 2005).

\section{2 (Des) encontros entre terapia ocupacional e fisioterapia}

É notada nas percepções de 07 gestores a confusão entre a atuação da terapia ocupacional e da Fisioterapia.

É um profissional que está ligado à fisioterapia, Tende muito a confusão com o profissional de fisioterapia, não é?E muitas das vezes os gestores acreditam que são o mesmo profissional e aí, algumas vezes você tem várias contrataçōes de fisioterapeutas e poucas contrataçôes de terapeutas ocupacionais, mas que säo profissionais diferentes (Gestor 04).

Eu sempre confundo os dois, fisioterapia e terapia ocupacional. Eles tem uma diferença, mas tem uma ligação também (Gestora 18).

O Conselho Regional de Fisioterapia e terapia ocupacional da 1 Regiáo traz as definiçóes acerca do objeto de estudo do fisioterapeuta e terapeuta ocupacional, respectivamente, como:

O profissional da fisioterapia tem como objeto de estudo o movimento humano. É ele quem avalia, previne e trata os distúrbios da cinesia humana, sejam decorrentes de alteraçóes de órgáos e sistemas ou com repercussões psíquicas e orgânicas (CONSELHO..., 2018a).

O profissional que compreende a Atividade Humana como um processo criativo, criador, lúdico, expressivo, evolutivo, produtivo e de automanutenção e o homem, como um ser práxico, interferindo no cotidiano do usuário comprometido em suas funçóes práticas objetivando alcançar uma melhor qualidade de vida. O terapeuta ocupacional considera no indivíduo sua faixa etária e/ou desenvolvimento da sua formação pessoal, familiar e social (CONSELHO..., 2018b).

Por essas definiçóes se notam as diferenças dos objetos de estudo de cada um desses profissionais, enquanto um se debruça na busca da compreensão e da intervenção no Movimento Humano, o outro tem sua ação voltada para a Ocupação Humana.

Embora essas profissôes tenham distintos objetos de estudo e intervençáo, alguns aspectos as aproximam. Para além de terem o mesmo órgão regulamentador (Sistema COFFITO/CREFITO), outro aspecto que aproxima a prática desses profissionais é a atuação/inserçáo na área de Reabilitação. No que alude à constituição das duas profissóes aqui no Brasil, Silva (2017) refere:

As demandas sociais relacionadas à reabilitação e inserção social de pessoas com incapacidades físicas motivou a criação dos primeiros cursos de formação de fisioterapeutas e terapeutas ocupacionais, que foram reconhecidos como cursos de Reabilitação (SILVA, 2017, p. 164).

O autor afirma ainda que, apesar das profissōes se constituírem de forma distintas, a origem da formação nos Cursos de Reabilitação desses profissionais no Brasil colaborou para um conflito de compreensão, entendida como sendo uma classe única de profissionais voltada apenas para essa área.

Essas confusóes se dáo também devido aos modelos adotados por alguns terapeutas ocupacionais, que acabam se desconectando do objetivo e objeto profissional da terapia ocupacional. Um exemplo desse aspecto é citado por Cruz (2018) que destaca que os modelos biomecânicos e cinesiológicos utilizados por alguns terapeutas ocupacionais não abrangem a dimensão holística do olhar desse profissional para a vida e o cotidiano das pessoas, limitando assim o processo de trabalho do profissional. É necessário ter clareza ao definir a forma de avaliar e de traçar objetivos no cuidado das pessoas que precisam de um tratamento de reabilitação física.

Além dos modelos de intervenção, destaca-se também o uso de abordagens e técnicas que podem ser igualmente empregados nas práticas dos dois profissionais, porém o que diferencia serão as finalidades.

$\mathrm{Na}$ terapia ocupacional, abre-se a mão para o fazer diário com significados, para o gesto, 
para o sentir, para o tocar, para dar e receber objetos ou para expressar uma forma de ser e estar no mundo. Para terapeutas ocupacionais, essa técnica, dentro de uma abordagem, é um meio e não um fim (CRUZ, 2018, p. 506).

Sendo assim, um dos pontos que estabelece a diferença entre as duas profissóes é que para a terapia ocupacional o fim não é aquisição de movimento e sim a aquisição de habilidades práticas a partir dos movimentos restabelecidos na reabilitação e que facilitarão a inserção social desses indivíduos. Do mesmo modo, nas ações e programas na atenção básica aparecerão semelhanças e diferenças na atuação desses profissionais. $\mathrm{O}$ que unem essas profissóes dentro da atenção básica são as ações preventivas e a promoção à saúde na perceptiva, por exemplo, da educação em saúde (ROCHA; PAIVA; OLIVEIRA, 2012; REZENDE et al., 2009). Ainda sobre isso, as diferenças aparecem na atuaçáo de núcleo profissional, como por exemplo, o terapeuta ocupacional irá

Promover a saúde, a independência e a autonomia no cotidiano, quanto ao desempenho ocupacional; atividades de vida diária e instrumentais de vida diária; trabalho e lazer; acessibilidade; desmonte de processos de segregação e exclusão social; emancipação social; desenvolvimento socioambiental, econômico e cultural e estimular a participação e inclusão social da pessoa, família, grupos (ROCHA; PAIVA; OLIVEIRA, 2012, p. 357).

Nesse sentido, essas profissóes abrangem o estudo do ser humano holisticamente, porém atuará conforme o que estabelece seus objetos de formação e atuação, e constituem conexôes a partir de modelos e abordagens que assumem na prática ou ainda pelas açóes que o serviço de saúde propóe a integralidade do cuidado e dos trabalhadores em prol da saúde da comunidade.

\subsection{Processos de contratação de terapeutas ocupacionais}

O processo seletivo dos profissionais de saúde para a atuação na Atenção Básica em João Pessoa dá-se através de análise de currículo, avaliação com situaçóes-problemas ocorridas nas microrregiôes do território para apreciar o perfil desse profissional e entrevista.

O profissional do NASF deixa seu curriculo e faz uma entrevista. É uma contratação, não é concurso público, tem entrevista e análise de currículo [...]. Quem tem aquela indicação, dá uma força. A gente sabe que isso existe em qualquer meio, não é? Então, existem essas duas maneiras, ou por esse processo seletivo, mais rigoroso, com entrevista, análise de curriculo e também tem a parte da pessoa ser indicada, por um politico, por parente, por alguma coisa desse tipo, que náo deixa de ser também um processo seletivo, no sentido de que você não vai indicar uma pessoa que tenha processo ruim (Gestor 04).

O curriculo é submetido e uma entrevista, e aí, conforme o perfil que se espera para o serviço [...]. São avaliados conhecimento do SUS, da Atenção Básica, do trabalho em equipe [...] (Gestora 15).

A questão do terapeuta ocupacional é que é nova, $e$ ainda está sendo pensado como vai ser essa adesão para contratação. A gente contrata assim: tem uma seleção ou às vezes por substituição dentro do municipio, por exemplo. Se eu já tenho essa profissão, se já tenho esse profissional lá (no serviço), eu tenho que ver se realmente tem um processo de substituição, mas como ela é uma profissão nova a gente ainda tá avaliando a questão da contratação se vai inserir e como a gente vai inserir. A gente tem que avaliar porque tem toda uma questão de orçamento (Gestora 03).

Para construirmos pontes de diálogo e avançar nas discussóes sobre a contratação do profissional de terapia ocupacional é necessário ponderar algumas questóes que se destacaram nas falas dos gestores. Ampliando a lista de contratações no município de João pessoa para além da Atenção Básica e de acordo com o Portal da Transparência da Prefeitura Municipal de João Pessoa, o município apresenta um quadro de 4.634 trabalhadores efetivos (contratação via concurso público) vinculados ao Fundo Municipal de Saúde, dos quais apenas um é terapeuta ocupacional e atua no âmbito hospitalar. Constando assim, que no município de João Pessoa, no que se refere à contratação pela Prefeitura municipal, apenas duas terapeutas ocupacionais contratadas, uma no âmbito da Atenção básica e outra no âmbito hospitalar.

Possivelmente, essa configuração é oportunizada pela prática clientelista fortemente presente na construção política do Nordeste brasileiro. Potter e Caetano (1998) dimensionam que o clientelismo é a relação de poder entre personalidades políticas, que oferece favores políticos como empregos, equipamentos, serviços de saúde entre outras situaçóes, em contrapartida de apoio político, no voto ou na fidelidade partidária. "Nesse sentido, as relaçóes clientelistas se dão entre os diferentes níveis do poder público e entre políticos e setores pobres da população" (POTTER; CAETANO, 1998, p. 152). 
Essa prática precariza os vínculos empregatícios, fazendo com que políticos e gestores coloquem as necessidades individuais ou de mercado na frente das necessidades da população. Os dados supracitados do Portal da Transparência apontam uma lacuna no que se refere à inserção dos terapeutas ocupacionais nos serviços de Saúde em João Pessoa. Nesse sentido, além da Atenção Básica, o terapeuta ocupacional pode se inserir nos serviços de saúde como: Academias de Saúde, Hospitais, Unidades de Pronto Atendimento, Centros de Atenção Psicossociais, Policlínicas Municipais, Centro Especializados de Saúde, Residências Terapêuticas, Centros de Referência em Saúde do Trabalhador.

Essa insuficiência atrelada aos interesses pessoais e políticos, supostamente, pode fazer com que os números de contrataçóes de outras profissóes aumentem como, por exemplo, o número de fisioterapeutas, retomando a fala de um dos entrevistados ele aponta

\section{[...] muitas das vezes os gestores acreditam que são o mesmo profissional e aí, algumas vezes você tem várias contrataçöes de fisioterapeutas e poucas contrataçôes de terapeutas ocupacionais (Gestor 04).}

Esse fato também aponta uma questáo de mercado existente no município. No site do E-MEC (2018) constam oito universidades/faculdades com cursos ativos de Fisioterapia em João Pessoa, em contrapartida apenas um curso ativo de terapia ocupacional, o que consequentemente gera demanda para o mercado de trabalho, considerando que anualmente uma média de 1.180 alunos ingressam nos cursos de Fisioterapia das oito universidades. Isso reflete no quantitativo de fisioterapeutas no quadro de efetivos do município (39 profissionais) em comparação com o de terapeutas ocupacionais (1 profissional).

Segundo a coordenaçáo do curso de terapia ocupacional da Universidade Federal da Paraíba, até o mês de outubro de 2018, dentro de quase 10 anos de atividade, há cerca de 175 egressos foram disponibilizados para o mercado de trabalho. Diante desse panorama político e de pressão mercadológica, os desafios de inserção desses terapeutas ocupacionais estâo postos: as articulaçôes políticas que se fazem necessárias para que os espaços de atuação sejam ocupados, a busca pela desprecarização nas contrataçóes, açôes para a divulgação acerca da prática desse profissional e a inserção dos terapeutas ocupacionais nos espaços políticos de decisão, fortalecendo o papel de articulador político desse profissional.

\section{Considerações Finais}

A partir deste estudo pôde-se observar que os gestores possuem algum conhecimento sobre a terapia ocupacional. Embora nem sempre compreendam ao certo o que este profissional pode fazer e trazem em suas falas elementos centrais que caracterizam a prática desse profissional. Observa-se ainda que os entrevistados associam a terapia ocupacional às áreas da Reabilitação Física e da saúde mental e às adaptaçóes feitas nos utensílios e atividades cotidianas das pessoas atendidas, bem como apresentam confusão em relação às diferenças entre a fisioterapia e a terapia ocupacional. No que diz respeito à forma de contratação, os gestores referem que a maior parte se dá por contratação e que a indicação política pode influenciar essa contratação.

O estudo possibilitou ainda a reflexão acerca de questóes importantes que se relacionam a inserção da terapia ocupacional na Atenção Básica, como por exemplo: o que tem impedido a inserção de terapeutas ocupacionais na Atenção Básica de João Pessoa? Que desafios precisam ser enfrentados para que os terapeutas ocupacionais possam inserir-se nesses serviços? Sendo assim, esse estudo possui um caráter político, no sentido de trazer questóes importantes relacionadas ao empoderamento dos terapeutas ocupacionais, impulsionando-os a ir em busca dos espaços de atuação.

Levando em consideração a hipótese de que os gestores não reconheciam o trabalho do terapeuta ocupacional na Atenção Básica, vale salientar que mesmo sendo superficial o conhecimento sobre a atuação, eles trouxeram a essência do objeto de formação e trabalho do terapeuta ocupacional. Não obstante, deve-se avançar nos diálogos em busca de uma formação interprofissional que aproxime as açóes de outros profissionais e possibilite que o reconhecimento seja uma realidade.

Outro aspecto se refere ao fato de que as instâncias contratantes precisam reavaliar o formato do processo seletivo para contrataçôes de profissionais da saúde, incluindo o terapeuta ocupacional. É necessário pensar na possibilidade do concurso público para evitar a precarização dos vínculos e extinguir as práticas clientelistas. Essa forma de contrataçáa vigente no município deve ser superada para que haja de fato um atendimento mais universal, equânime e integral que responda às necessidades dos usuários.

Sendo assim, posteriormente se faz necessário um diálogo sobre os resultados deste estudo, juntamente com os gestores participantes e demais autoridades, para ampliar as discussôes e fomentar ideais de inserção dos terapeutas ocupacionais nesse município. Faz-se necessário também a continuidade dessa temática e desenvolvimento de estudos semelhantes para o avanço desses conteúdos. 


\section{Referências}

ANTUNES, M. H.; ROCHA, E. F. Desbravando novos territórios: incorporação da Terapia Ocupacional na estratégia da Saúde da Família no município de São Paulo e a sua atuação na atenção à saúde da pessoa com deficiência - no período de 2000-2006. Revista de Terapia Ocupacional da Universidade de São Paulo, São Paulo, v. 22, n. 3, p. 270-278, 2011.

ASSOCIAÇÃO AMERICANA DE TERAPIA OCUPACIONAL - AOTA. Estrutura da prática da terapia ocupacional: domínio \& processo - $3^{\text {a }}$ edição. Revista de Terapia Ocupacional da Universidade de São Paulo, Sáo Paulo, v. 1, n. 26, p. 1-49, 2013.

BAISSI, G.; MAXTA, B. S. B. Experiência da terapia ocupacional no cuidado familiar em um serviço de Atenção Primária em Saúde. Cadernos de Terapia Ocupacional da UFSCar, São Carlos, v. 21, n. 2, p. 413-422, 2013. http:// dx.doi.org/10.4322/cto.2013.043.

BARDIN, L. Análise de conteúdo. São Paulo: Persona, 1977.

BATTISTEL, A. L. H. T. História oral de professores de terapia ocupacional: três vidas, três histórias, quatro cantos do Brasil. 2016. 309 f. Tese (Doutorado em Educação) Universidade Federal de Santa Maria, Santa Maria, 2016.

BRASIL. Lei $n^{\circ} 8080$, de 19 de setembro de 1990. Dispóe sobre as condiçóes para a promoção, proteção e recuperação da saúde, a organização e o funcionamento dos serviços correspondentes e dá outras providências. Diário Oficial [da] República Federativa do Brasil, Poder Executivo, Brasília, DF, 19 set. 1990. Disponível em: <http://www.planalto. gov.br/ccivil_03/leis/L8080.htm>. Acesso em: 2 abr. 2017.

BRASIL. Ministério de Saúde. Profissionalização dos auxiliares de Enfermagem. Brasília, 2003.

BRASIL. Portaria n ${ }^{\circ} 154$, de 24 de janeiro de 2008. Cria os Núcleos de Apoio à Saúde da Família - NASF. Diário Oficial [da] República Federativa do Brasil, Poder Executivo, Brasília, DF, 24 jan. 2008. Disponível em: <http://bvsms. saude.gov.br/bvs/saudelegis/gm/2008/prt0154_24_01_2008. html>. Acesso em: 2 abr. 2017.

BRASIL. Constituição da República Federativa do Brasil. Texto constitucional promulgado em 5 de outubro de 1988, com as alterações adotadas pelas Emendas Constitucionais nos 1/1992 a 68/2011, pelo Decreto Legislativo no 186/2008 e pelas Emendas Constitucionais de Revisão nos 1 a 6/1994. Brasília: Câmara dos Deputados, 2012.

BRASIL. Ministério da Saúde. Secretaria de Atenção à Saúde. Núcleo de Apoio à Saúde da Família. Brasília, $2014 \mathrm{a}$.

BRASIL. Ministério da Saúde. Secretaria de Atenção à Saúde. Departamento de Atenção Básica. Colocando o NASF em Operação. Brasília, 2014b. (Cadernos da Atenção Básica: Núcleo de Apoio à Saúde da Família).

BRASIL. Ministério da Saúde. Portal Sistema Único de Saúde. Brasília, 2017a. Disponível em: <http://portalsaude. saude.gov.br/index.php/cidadao/entenda-o-sus>. Acesso em: 2 abr. 2017.

BRASIL. Portaria no 2.436, de 21 de novembro de 2017. Aprova a Política Nacional de Atenção Básica, estabelecendo a revisão de diretrizes para a organização da Atenção Básica, no âmbito do Sistema Único de Saúde (SUS). Nova Política Nacional da Atenção Básica. Diário Oficial [da] República Federativa do Brasil, Poder Executivo, Brasília, DF, 21 nov. 2017b. p. 68-76.

CABRAL, L. R. S.; BREGALDA, M. M. A atuação da terapia ocupacional na atenção básica à saúde: uma revisão de literatura. Cadernos de Terapia Ocupacional da UFSCar, São Carlos, v. 25, n. 1, p. 179-189, 2017. http://dx.doi. org/10.4322/0104-4931.ctoAR0763.

CAMPOS, G. W. S. et al. Reflexões sobre atenção básica e estratégia de saúde da família. In: CAMPOS, G. W. S.; GUERRERO, A. V. (Org.). Manual de práticas de atenção básica: saúde ampliada e compartilhada. Sáo Paulo: HUCITEC, 2008. p. 247-272.

CARVAlHO, C. R. A. A identidade profissional dos terapeutas ocupacionais: consideraçóes a partir do conceito de estigma de Erving Goffman. Saúde e Sociedade, São Paulo, v. 21, n. 2, p. 364-371, 2012. http://dx.doi.org/10.1590/ S0104-12902012000200010.

CECCIM, R. B. Educação permanente em saúde: de s centralização e disseminação de capacidade pedagógica na saúde. Ciência \& Saúde Coletiva, Rio de Janeiro, v. 10, n. 4, p. 975-986, 2005. http://dx.doi.org/10.1590/ S1413-81232005000400020.

CONSELHO REGIONAL DE FISIOTERAPIA ETERAPIA OCUPACIONAL - CREFITO 1. O fisioterapeuta. Recife, 2018a. Disponível em: <http://crefito1.org.br/profissoes/ fisioterapia/>. Acesso em: 8 out. 2018.

CONSELHO REGIONAL DE FISIOTERAPIA E TERAPIA OCUPACIONAL - CREFITO 1. O terapeuta ocupacional. Recife, 2018b. Disponível em: <http:// crefito1.org.br/profissoes/terapia-ocupacional/>. Acesso em: 8 out. 2018 .

CRUZ, D. M. C. Os modelos de terapia ocupacional e as possibilidades para prática e pesquisa no brasil. Revista Interinstitucional Brasileira de Terapia Ocupacional, Rio de Janeiro, v. 2, n. 3, p. 504-517, 2018.

CRUZ, D. M. C.; SOUZA, F; EMMEL, M. L. G. Formação do terapeuta ocupacional para a gestão. Revista de Terapia Ocupacional da Universidade de São Paulo, São Paulo, v. 25, n. 3, p. 309-316, 2014. http://dx.doi.org/10.11606/ issn.2238-6149.v25i3p309-316.

DOMINGOS, J. M.; KEBBE, L. M. Atuação na área de saúde mental: perspectiva de estudantes de um curso de graduação em terapia ocupacional. Cadernos de Terapia Ocupacional da UFSCar, São Carlos, v. 24, n. 2, p. 305-314, 2016. http://dx.doi.org/10.4322/0104-4931.ctoAO0616.

DUBAR, C. A crise das identidades: a interpretação de uma mutação. Porto: Afrontamento, 2006.

E-MEC. Ministério da Educação. Consulta avançada por curso. Brasília, 2018. Disponível em: <http://emec.mec. gov.br/>. Acesso em: 9 out. 2018.

FARIAS, I. Neurologia adulto: disfunções neurológicas. In: CAVALCANTI, A.; GALVÁO, C. (Ed.). Terapia 
ocupacional: fundamentação \& prática. Rio de Janeiro: Guanabara Koogan, 2007. p. 187-215.

FURLAN, P. G.; OLIVEIRA, M. S. Terapeutas ocupacionais na gestão da atenção básica à saúde. Cadernos de Terapia Ocupacional da UFSCar, São Carlos, v. 25, n. 1, p. 21-31, 2017. http://dx.doi.org/10.4322/0104-4931.ctoAO0781.

GALHEIGO, S. O cotidiano na terapia ocupacional: cultura, subjetividade e contexto histórico-social. Revista de Terapia Ocupacional da Universidade de São Paulo, São Paulo, v. 14, n. 3, p. 104-109, 2003.

JOÃO PESSOA. Prefeitura Municipal. Secretaria Municipal de Saúde - SMS. Plano Municipal de Saúde 2014-2017. João Pessoa, 2014.

JOÃO PESSOA. Prefeitura de João Pessoa. Portal da Transparência. Despesas com pessoal. João Pessoa, 2018. Disponível em: <https://transparencia.joaopessoa.pb.gov. br/\#/pessoal>. Acesso em: 08 out. 2018.

LIMA, A. C. S.; FALCÃO, I. V. A formação do terapeuta ocupacional e seu papel no Núcleo de Apoio à Saúde da Família - NASF do Recife, PE. Cadernos de Terapia Ocupacional da UFSCar, São Carlos, v. 22, n. 1, p. 3-14, 2014. http://dx.doi.org/10.4322/cto.2014.002.

LIMA, E. M. F. A.; OKUMA, D. G.; PASTORE, M. N. Atividade, ação, fazer e ocupação: a discussão dos termos na terapia ocupacional brasileira. Cadernos de Terapia Ocupacional da UFSCar, São Carlos, v. 21, n. 2, p. 243254, 2013. http://dx.doi.org/10.4322/cto.2013.026.

MARCOLINO, T. Q. et al. Comunidade de prática em terapia ocupacional para o cuidado em saúde mental na Atenção Básica em saúde: expectativas e impactos. Cadernos de Terapia Ocupacional da UFSCar, São Carlos, v. 24, n. 4, p. 733-741, 2016. http://dx.doi.org/10.4322/01044931.ctoAO0788.

MERHY, E. E.; MALTA, D. C.; SANTOS, F. P. Desafios para os gestores do SUS, hoje: compreender os modelos de assistência à saúde no âmbito da Reforma Sanitária brasileira e a potência transformadora da gestâo. Niterói: UFF, 2018. Disponível em: <http://www.uff.br/saudecoletiva/professores/ merhy/indexados-30.pdf>. Acesso em: 6 mar. 2018.

MIRANDA, A. S. A gestão de equipes da estratégia de saúde da família. In: SOUSA, M. F.; FRANCO, M. S.; MENDONÇA, A. V. M. (Ed.). Saúde da Família nos municipios brasileiros: os reflexos dos 20 anos no espelho do futuro. Campinas: Saberes, 2014. p. 323-354.

ORGANIZAÇÃO PAN-AMERICANA DA SAÚDE. Educação interprofissional na atençâo à saúde: melhorar a capacidade dos recursos humanos para alcançar a saúde universal. Washington: OPAS, 2016. Relatório da reunião Bogotá, Colômbia 7 a 9 de dezembro de 2016.

PEDUZZI, M. O SUS é interprofissional. Interface Comunicação, Saúde, Educação, Botucatu, v. 20, n. 56 , p. 199-201, 2016. http://dx.doi.org/10.1590/180757622015.0383 .

PELOZI, M. B. O papel do terapeuta ocupacional na tecnologia assistiva. Cadernos de Terapia Ocupacional da UFSCar, São Carlos, v. 13, n. 1, p. 39-45, 2005.

POTTER, J. E.; CAETANO, A. J. Clientelismo e esterilização no nordeste brasileiro 1986-1995. In: ENCONTRO NACIONAL DE ESTUDOS POPULACIONAIS, 11. 1998, Caxambu. Anais... Caxambu: ABEP, 1998. p. 151-182.

REEVES, S. et al. Interprofessional education: effects on professional practice and healthcare outcomes (update). Cochrane database of systematic reviews. Cochrane Database of Systematic Reviews, Oxford, n. 3, p. CD002213, 2013. PMid:23543515.

REZENDE, M. et al. A equipe multiprofissional da Saúde da Família: uma reflexão sobre o papel do fisioterapeuta. Ciência \& Saúde Coletiva, Rio de Janeiro, v. 14, n. 1, p. 1403-1410, 2009. Suplemento 1. http://dx.doi.org/10.1590/ S1413-81232009000800013.

ROCHA, E. F.; PAIVA, L. F. A.; OLIVEIRA, R. H. Terapia ocupacional na Atenção Primária à Saúde: atribuiçôes, açóes e tecnologias. Cadernos de Terapia Ocupacional da UFSCar, São Carlos, v. 20, n. 3, p. 351-361, 2012. http:// dx.doi.org/10.4322/cto.2012.035.

SANTOS, M. Saúde e ambiente no processo de desenvolvimento. Ciência \& Saúde Coletiva, Rio de Janeiro, v. 8, n. 1, p. 309-314, 2003. http://dx.doi.org/10.1590/ S1413-81232003000100024.

SCHRAIBER, L. B. et al. Planejamento, gestão e avaliação em saúde: identificando problemas. Ciência \& Saúde Coletiva, São Paulo, v. 4, n. 2, p. 221-242, 1999. http:// dx.doi.org/10.1590/S1413-81231999000200002.

SILVA, D. B. A terapia ocupacional no Brasil na perspectiva sociológica. 2017. 476 f. Tese (Doutorado em Sociologia) - Universidade Federal do Paraná, Curitiba, 2017.

UNIVERSIDADE DE SÃO PAULO - USP. Faculdade de Medicina de Ribeirão Preto - FMRP. Terapia ocupacional. Ribeirão Preto, 2018. Disponível em: <http://www.fmrp. usp.br/site-graduacao/graduacao/cursos-oferecidos-pelafmrp/terapia-ocupacional/>. Acesso em: 12 fev. 2018.

WORLD HEALTH ORGANIZATION - WHO. Framework for action on interprofessional education o collaborative practice. Geneva: WHO, 2010.

\section{Contribuição dos Autores}

Erickson Franklin dos Santos Miranda foi responsável pela coleta de dados, captação de materiais para referências e redação do texto. Cláudia Fell Amado foi responsável pela organização das fontes e análises e revisão. Thayane Pereira da Silva Ferreira foi responsável pela captação de referências e revisão da escrita. Todos os autores aprovaram a versão final do texto. 